\title{
Application-Oriented Professional Curriculum Framework Model Based on Big Data Technology
}

\author{
Xiao-Ling WU and Allam MAALLA* \\ Research Institute of Open Data Commercial Application, School of Information Technology \\ and Engineering, Guangzhou College of Commerce, Guangzhou, China, 511363 \\ wyky360@163.com \\ * Correspondence: allammaalla@yahoo.com
}

Keywords: Applied talent; Course framework model; Big Data; Corporate Recruitment

\begin{abstract}
This paper focuses on the scientific design of the "application-oriented talent training curriculum framework", the construction of data science and engineering major in Guangzhou college of commerce, and the use of big data technology to achieve curriculum design as an example to provide reference for the design and practice of the university's "application-oriented curriculum system". The paper puts forward an opinion that understanding and practice of applied specialty has the characteristics of "periodicity" and "phasedness". In this paper, the idea of dividing the ability according to the position and the requirements of the knowledge module is proposed, and the general model of the applied curriculum framework is formed. by using the knowledge of web crawler, natural language processing, knowledge acquisition principle, etc., the data analysis process and implementation method of course framework based on enterprise recruitment are proposed.
\end{abstract}

\section{Introduction}

Applied talents are a hot topic in the cultivation of many colleges and universities. The design of the professional curriculum system is the action program for talent training. The correctness and rationality of the curriculum system design determines the direction and quality of talent training. The process of cultivating talents, from the perspective of human acquisition of knowledge, is the process of assisting them in constructing their own knowledge management systems and applying knowledge. Therefore, the core problem of the design and practice of the curriculum system is: what is the knowledge field of talent cultivation, and what is the architecture of the knowledge field. Correspondingly, the current talent training in colleges and universities has problems such as the disconnection between teaching content and social needs, the fragmentation of students' knowledge chain, and the inefficiency of internalization of students' knowledge. The determination of the traditional professional knowledge course depends more on the subjective experience and feelings of the professional construction team. Therefore, the quality of the professional course system design is determined by the individual knowledge level and intuitive feeling. It is not known that the curriculum knowledge is systematic, the order of the arrangement is reasonable, and the requirements of the enterprise are consistent. So there is a possibility that Course knowledge is not systematic, the order of arrangement is unreasonable, and it is inconsistent with the needs of enterprises.

Therefore, it makes sense to study the rules of designing "application-oriented" professional training curriculum framework. With more reliable and scientific 
decision-making means such as big data analysis and mining to design the framework for the implementation of the application-oriented talent training curriculum system, the application of talent training guidance could have a good reference.

\section{The Key Issues of Curriculum System Design with Big Data Technology}

\section{The Basic Framework of the Professional Curriculum System}

Looking at the design of professional curriculum systems in various universities, the content generally includes two parts, professional knowledge and ability requirements. Designing a professional curriculum system is actually designing a knowledge tree for its industry domain. From a macro perspective, the fragment knowledge what Students have learn depends on the content integrity and system of the professional knowledge chain. According to the research knowledge in the field of knowledge network, knowledge is static, knowledge is applied through flow, and human ability can be increased when they apply related knowledge to solve problems. Applied talent emphasizes the application of knowledge to solve industry problems. Therefore, the curriculum system and competency framework designed under the concept of "domain problem has life cycle" has universal applicability to the construction of "engineering" professional applied talent training curriculum system.

\section{The Key Link of Data Mining}

The advanced nature of the data analysis and mining model principle and the effectiveness of its application have been recognized and enthusiastically in the industry in recent years. However, the object of data analysis is "data", there is no data, and data decisions are empty talk. When we apply big data technology to the design of professional curriculum system, the most critical part is to obtain the relevance, representativeness and real-time of the data. At present, most of the colleges and universities have such problems as the acquisition channels, the small data scale, the outdated time, and the rough content etc. Therefore, obtaining a more comprehensive, objective and real-time sample of enterprise data, and using big data technology to refine the process of design curriculum system, is the primary solution to the scientific design curriculum system. Now network recruitment information is definitely large-scale data, smooth channel, real-time frontier, and high value density data. Using web crawler technology, in-memory database and non-relational database technology, large-scale batch crawling and storage of online recruitment information can be realized.

\section{Course System Framework Design Ideas}

The first and most important thing to build a curriculum framework is to use big data technology is to construct a professional curriculum knowledge chain. The process of learning knowledge corresponds to the process of solving domain problems, and each process requires relevant capabilities for the application of knowledge. That is to say, under the guidance of the concept of "the domain problem has a life cycle", a corresponding capability requirement chain is formed, and accordingly, the corresponding knowledge module requirements are required. The process of its construction is shown in the following figure: 


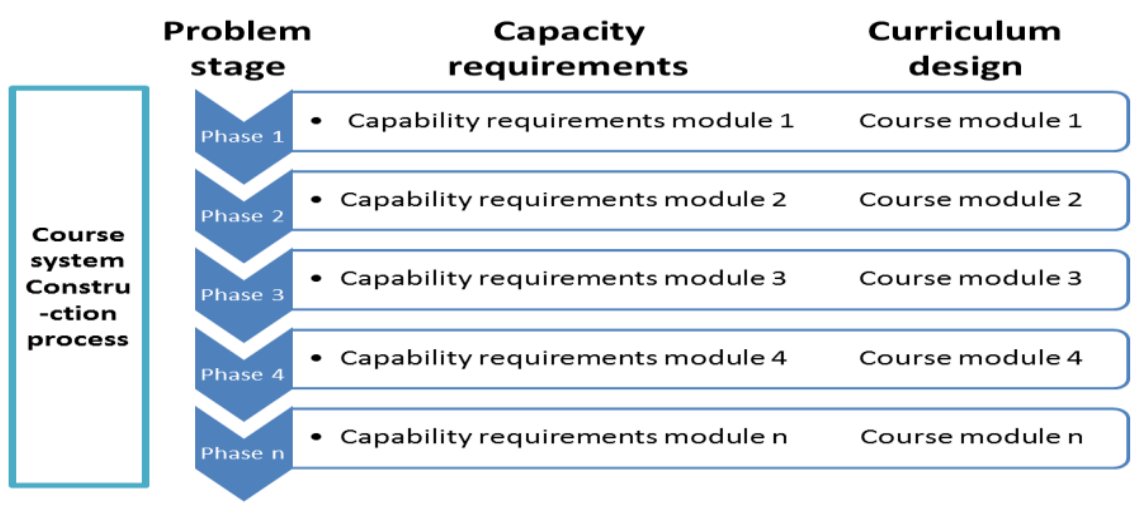

Figure 1. Personnel training course system framework

There are two main core issues involved in the curriculum framework:

1 What is the general process for dealing with problems in this industry sector?

2 How do each process flow, capability module, and course module correspond to conversion?

The general process of dealing with problems in various industry sectors needs to be linked to specific industries. The determination of this general process needs to be determined by a person skilled in the field. And how are the capability modules and course modules that are the main content of the course framework derived from the corresponding process flow? On the whole, the entire industry domain problem can be dismantled into multiple processing processes, and each process is composed of relatively simple small problems. With regard to the definition of "solving problems", psychology is interpreted as the process of solving problems by a series of thinking operations, which are caused by certain scenarios, applying various cognitive activities and skills according to certain goals. In the process of different object transformation stages, people understand the content and level of the object, the application methods and tools, and the thinking process is different. The course knowledge module is mainly composed of identifying the object of recognition and using the reformer. What we have to do is to use the big data technology to process and extract the network recruitment information, and find the information about the learning knowledge, tools and capabilities corresponding to each process stage, so as to form the corresponding talent training curriculum system.

\section{Curriculum Framework Design Implementation Path}

The general process of data analysis and mining is generally: business target analysis, data collection, data storage and management, data modeling and analysis, data interpretation and application. According to construct "the knowledge structure of the industry domain", the path of designing a curriculum structure can be realized by designing the process such as data source type screening and collection, data storage and management scheme, data modeling analysis selection technology, data interpretation application mode, etc. The following is a data analysis and mining process design for this problem.

It can be seen from the design framework of the curriculum system of Figure 1 . The application-oriented curriculum framework based on the cultivation of practical ability consists of three parts, the business process chain, the capability component chain, and the course module chain. The business process chain can be referenced by experts in the field, and the design of the capability component chain and the course module chain involves the 
exploration and research of the relationship between professional competence and curriculum. Since the main channel for teaching knowledge is the curriculum, the relationship between professional competence and curriculum content is the discussion of the relationship between professional competence and knowledge. According to the hierarchical structure of knowledge, for individuals, knowledge is divided into cognitive and skill layers. Individuals' perception of knowledge is a process of psychological cognition, and skills are often the process by which individuals learn through practice, comprehension, and experience in specific situations. Correspondingly, in the professional talent training curriculum system, the curriculum can also be divided into cognitive level and skill level. The cognitive level curriculum learning tasks are mainly concepts, principles, and law knowledge. The goal of the skill level course is to master the various skills to solve problems in related industry fields. In the course framework system, it often shows the use of tools, curriculum design, and graduation design courses. The process of conversion between knowledge and course is as follows:
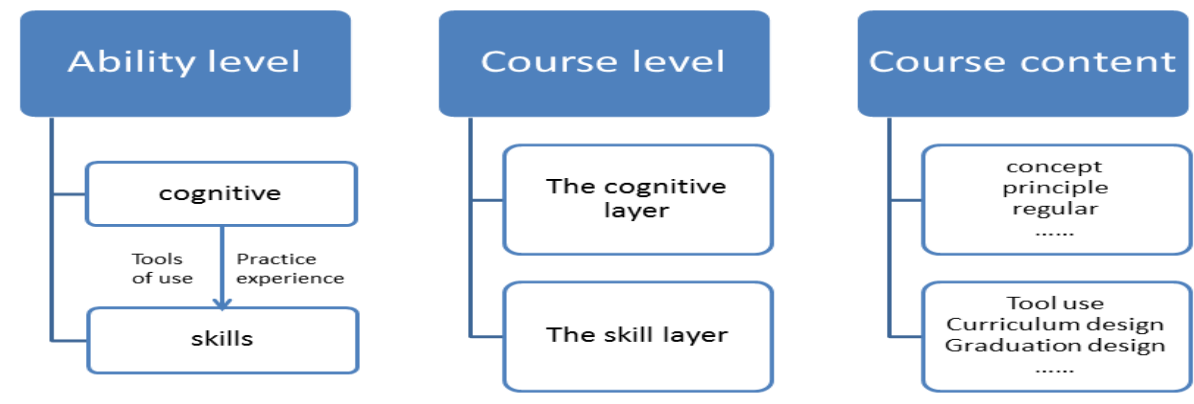

Figure 2. The relationship between curriculum and ability

Therefore, the curriculum system can be expressed in the following framework according to the relationship of business processes, knowledge, and capabilities:

\begin{tabular}{|c|c|c|c|c|}
\hline $\begin{array}{l}\text { Business } \\
\text { process: }\end{array}$ & $\begin{array}{cl}\text { Business } & \text { Business } \\
\text { phase 1 } & \text { phase 2 }\end{array}$ & $\begin{array}{l}\text { Business } \\
\text { phase } 3\end{array}$ & $\begin{array}{l}\text { Business } \\
\text { phase } n\end{array}$ & \\
\hline $\begin{array}{l}\text { Ability } \\
\text { level: }\end{array}$ & $\begin{array}{l}\text { cognitive } \\
\text { skills }\end{array}$ & $\begin{array}{l}\text { cognitive } \\
\text { skills }\end{array}$ & $\begin{array}{l}\text { cognitive } \\
\text { skills }\end{array}$ & \\
\hline $\begin{array}{l}\text { Course } \\
\text { level: }\end{array}$ & $\begin{array}{l}\text { Cognitive layer } \\
\text { Skill layer }\end{array}$ & $\begin{array}{l}\text { Cognitive layer } \\
\text { Skill layer }\end{array}$ & $\begin{array}{l}\text { Cognitive layer } \\
\text { Skill layer }\end{array}$ & $\begin{array}{c}\text { Cognitive layer } \\
\text { Skill layer }\end{array}$ \\
\hline $\begin{array}{l}\text { Course } \\
\text { content: }\end{array}$ & $\begin{array}{l}\text { concept/principle... } \\
\text { tool/case... }\end{array}$ & $\begin{array}{l}\text { concept/principle... } \\
\text { tool/case... }\end{array}$ & $\begin{array}{l}\text { concept/principle... } \\
\text { tool/case... }\end{array}$ & $\begin{array}{l}\text { concept/principle... } \\
\text { tool/case... }\end{array}$ \\
\hline
\end{tabular}

Figure 3. Curriculum system framework design ideas

It can be seen from the figure that the professional competence requirements of each business stage, including cognitive ability and skills, correspond to the knowledge structure requirements of the cognitive layer and the skill level.

\section{Design of Analysis Process That Transforms Professional Competence into Curriculum Structure}

In summary, the professional competence-course structure derivation process mainly includes two stages: "capability theme calculation" and "capability-curriculum structure 
transformation". The main process of the first phase of the "Capability Theme Calculation" is as follows:
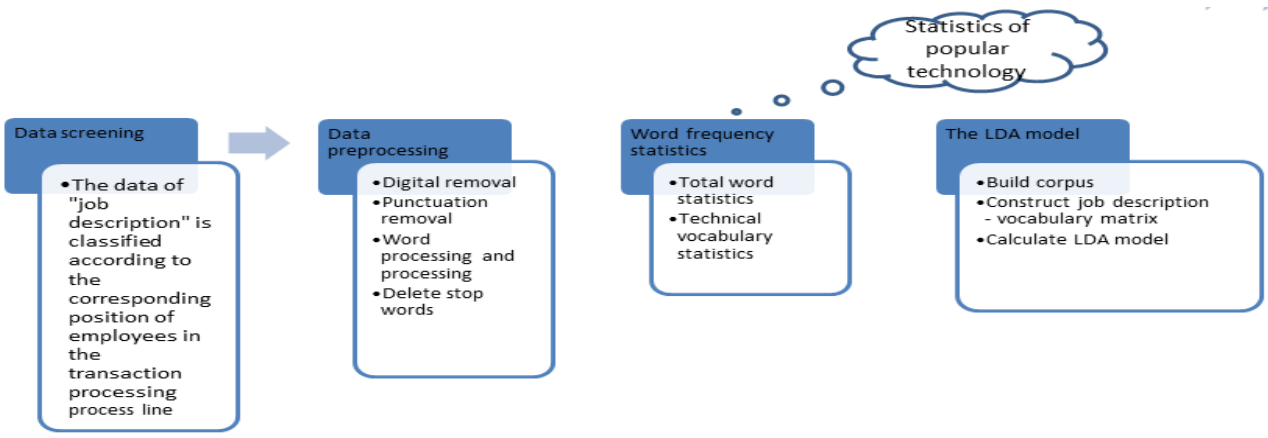

Figure 4. The data analysis process of "ability topic calculation

First, the positions are classified according to the corresponding "business stage", and the "post description" text data of each position category is preprocessed according to the division result using natural language processing technology. At the same time, the LDA topic model is applied to mine the "capability" topic model for the post description. In the word frequency statistics, the text related to the "business application tool" is analyzed to find out the hot technology, so that it can provide a reference for the selection of practical teaching tools.
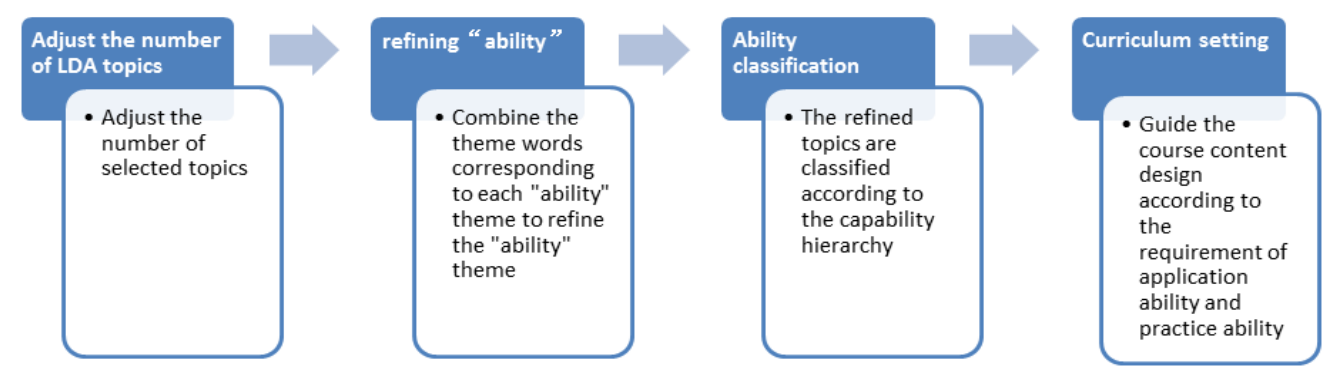

Figure 5. Capacity-course structure transformation" data analysis process

The second stage of the "capability - curriculum structure conversion" process is shown in Figure 8. The number of topics in the LDA model needs to be calculated according to multiple parameter adjustments to obtain a number of "capability topics" that are relatively independent and have a prominent theme. These topics are then manually refined and categorized with knowledge levels. Finally, these "capabilities topics" are divided into cognitive and skill layers, and the corresponding courses are assisted according to the course content form (concept principle class, case tool class, etc.).

\section{Summary}

This paper applies the big data application technology to the network recruitment data analysis, and puts forward the idea of talent capacity training and course content design according to the position type, which provides a method that can be imitated for the design of college application talent training program. At the same time, it is undeniable that in the implementation process of this method, there are differences in the design of curriculum frameworks applied by different professions. Compared with history, linguistics and other 
majors, the framework design method of talent ability and curriculum structure proposed in this paper has a better reference for "engineering" majors such as petroleum engineering, metallurgical engineering, transportation engineering, and other majors. These professions have business processes in their industries. The collection of online recruitment information is time-consuming, and is affected by computer computing power, the timeliness of online recruitment information, and the size of the sample. The network recruitment information collection task needs to be completed for a period of time. Data processing and analysis is a semi-automated process. In order to make the calculation results more accurate, pre-processing and modeling of network recruitment information requires the participation of industry experts. In addition, the design of talent training program does not mention the specific teaching implementation process. This paper focuses on providing practical methods for the design of application-oriented talent training program framework, designing the curriculum modules required for applied talents according to job requirements, focusing on knowledge level training and knowledge relationship.

\section{Acknowledgement}

This research was financially supported by the 2017 Higher Education Teaching Research and Reform Project of Guangdong Province, "The Big Data Talent Cultivation Practice Teaching System of Business Schools" (Project No. 2017SJJXGG01).Allam MAALLA* is corresponding author.

\section{References}

[1] Maalla A, Zhou C, Guang-Yu W U. The Construction of Heterogeneous Platform of Unified Service System Based on Cloud Computing [J]. 2017(cmee). DOI: $10.12783 / \mathrm{dtcse} / \mathrm{cmee} 2017 / 20056$.

[2] Patrick TH. Eugster, Pascal A. Felber, Rachid Guerraoui, and Anne-Marie Kermarrec. The Many Faces of Publish / Subscribe. ACM Computing Surveys, 35(2): 104-131, 2013.

[3] Maalla A (2016) Construction of Information Ecosystem on Enterprise Information Portal (EIP). J Electr Electron Syst 5: 205. Doi: 10.4172/2332- 0796.1000205.

[4] Denis Lehmann. Technology Selection for BI Architectures in the Big Data Era. 2016.

[5] Bernard Marr. Big Data: Using Smart Big Data Analytics and Metrics to make better Decisions and improve Performance. Wiley, 1st edition, 2015.

[6] Nathan Marz and James Warren. Big Data - Principles and best practices of scalable realtime data systems. 2015. 